\title{
A Teacher, a Totem, and a True Tropical Story: A Reading
}

\section{Hazel Menehira}

\author{
Trinity College London
}

A transformative spiritual experience with an Aboriginal rainforest family was not on the radar in 1999 when Hazel Menehira spent some spectacular months in Kuranda, Far North Queensland working with the Aboriginal Mayi Wunba (Native Honey Bee) Dance Troupe. The aim of this visit was to enhance the vocal strengths of the performance and to contribute text and dialogue required within the culture to include female dancers in the programme. This is my perspective of the cross cultural creative and spiritual impact of it. Embraced by the rainforest family this antipodean writer resident in Cairns since 2001 was in rich story territory. She has drawn on this experience and also her affiliated Maori cultural background to present stories grounded in unique indigenous values often rooted in past eras. You will hear some extracts from one such story called Hunting Grounds. It is fictional but many aspects of it resonate with the personal account given to me of one part of a Djabugay elder's ritual passage into manhood. The spiritual reconnection with this episode of my life came to the fore recently whilst writing my memoirs.

T et me take you on a journey. My thirteenth book, Nothing as Posh as a Memoir, will be launched next week in conjunction with my $80^{\text {th }}$ birthday.

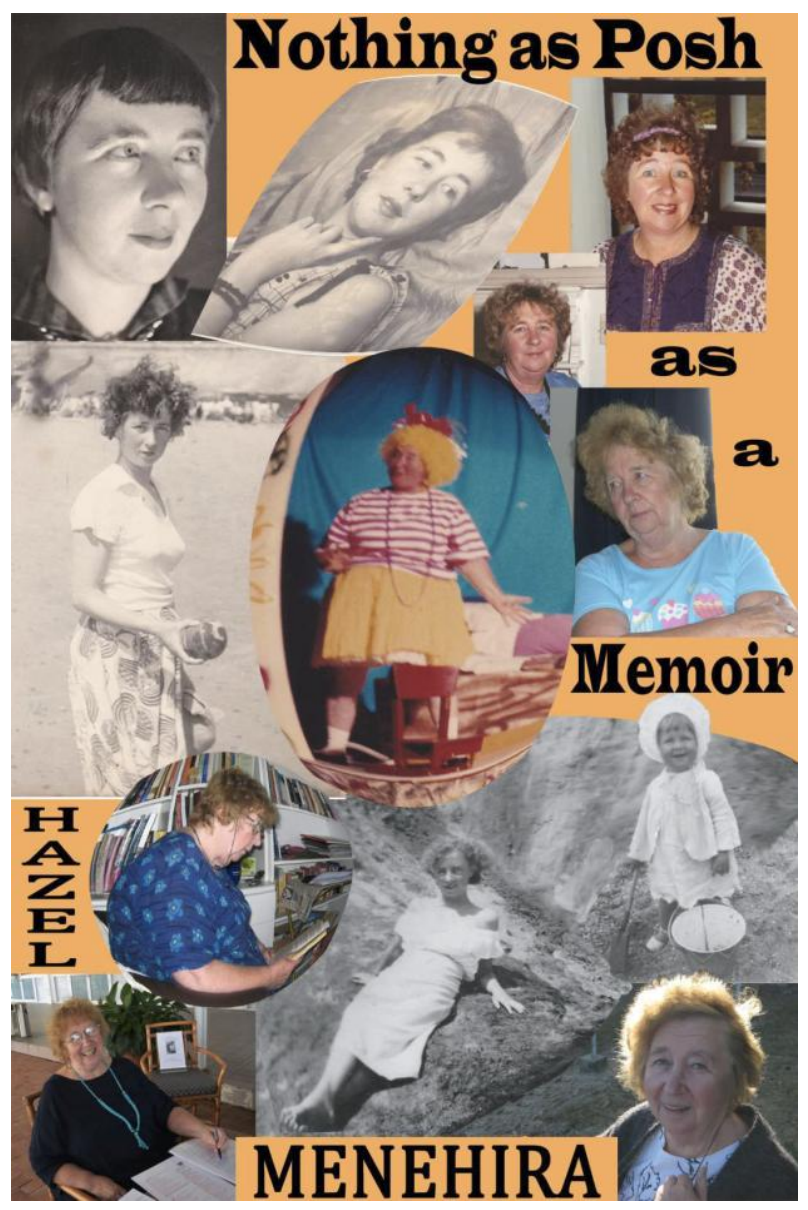


It has been said that writing a memoir is a unifying endeavour. For me it was a way of connecting both my outer and inner life over a long period.

In my book I describe how my love affair with Far North Queensland began more than 30 years ago. My holiday journals from 1984 until I settled here in 2001 reveal many aspects of the historical and cultural development of Cairns.

As a writer and a theatre director My interest in indigenous performance areas was nurtured by both the talent of my own whanau and writing colleagues in New Zealand, and by my work with Maori of all ages in theatre. I think one of the big highlights of this learning curve for me was in 1985 when I directed a large cast of Maori performers in the classic Bruce Mason drama Awatea.

It was in 1999 through a convergence of family, fate and travel that I discovered the Aboriginal Mayi-Wunba (Native Honey Bee) dancers in the Kuranda Markets. I was constantly in the audience there. The friendship between us strengthened and I had an urge to encourage the weaker voice aspects of the performance. You see the theatre tutor in me rose up. Together we worked on vocal strengths for a programme to include female dancers for the first time. Text and dialogue was necessary for this within appropriate parameters of the culture. Imagine my surprise when my first tutoring session designed for no more than eight performers involved 20 more family of all ages. Working with the group for three months was more than a learning curve. It was a transformative spiritual experience, as the elder of the family, his wife and extended family embraced me.

Observing Aboriginal culture I will not name the elder, though it is published in my book. Ensuring the duty of care requirements I must tell you I recently reconnected with this family after 15 years. They had just returned from the recent Laura Festival and reconnecting with them was an amazing experience. The youngsters were now men. The matriarch of the family gave me full permission to use the material I am showing you...in fact they were all delighted that I had kept photographs and records-including programme notes of the eventual polished performance. Herewith captions are some of the original troupe shown with the indigenous protocol warning that some deceased members are included.

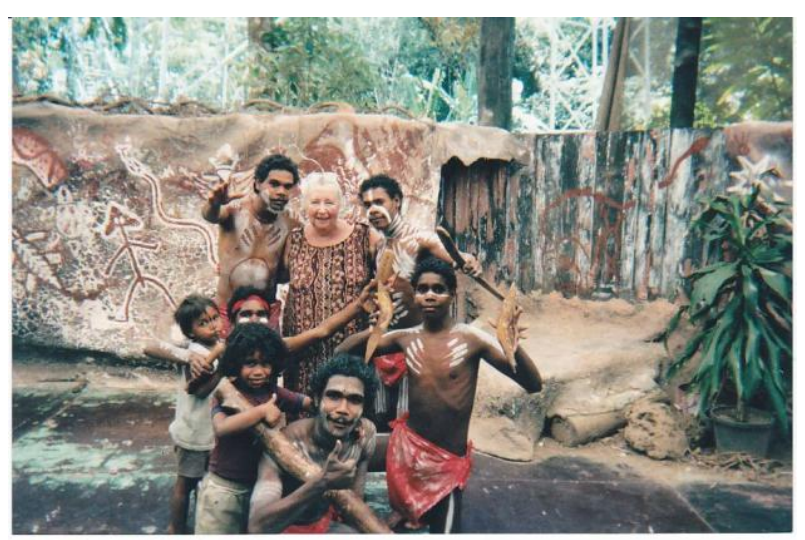

Friendship in the Market Place

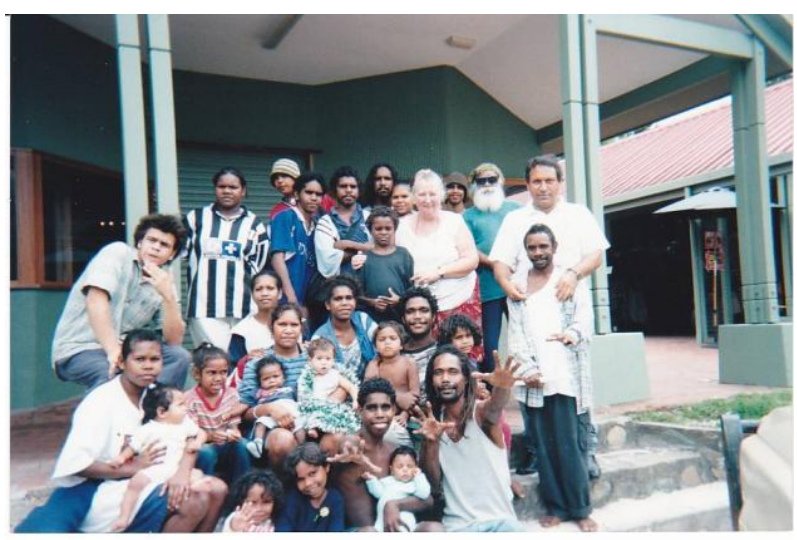

Meeting the Mayi Wunba Performers 


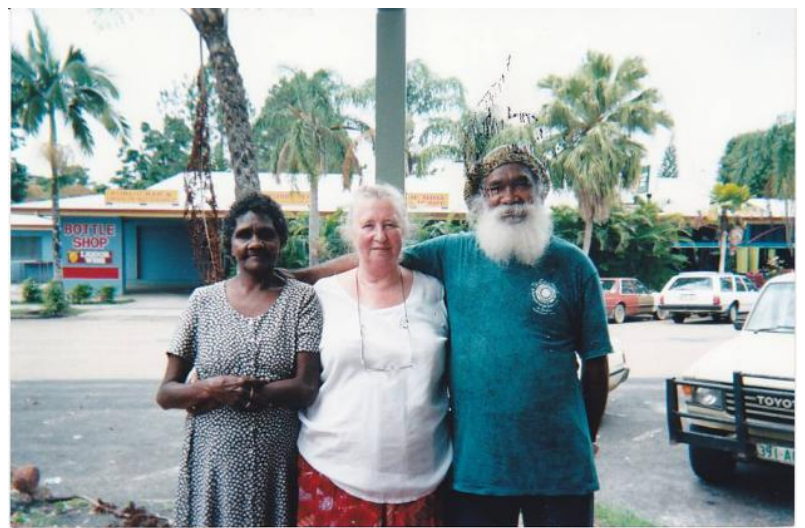

My Rainforest Elders

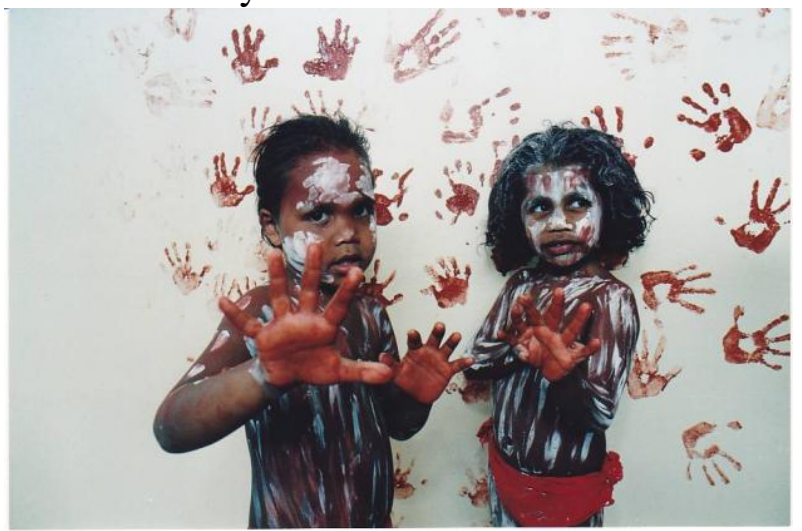

Ready for Performance

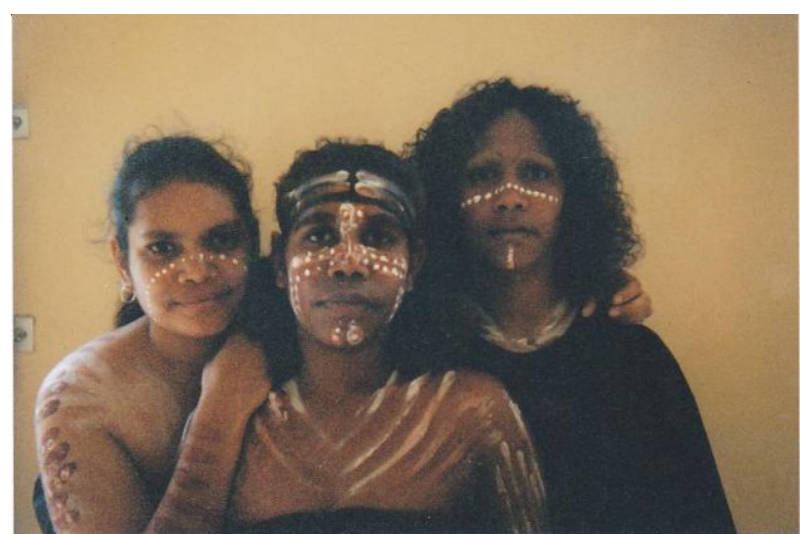

Beautiful New Friends

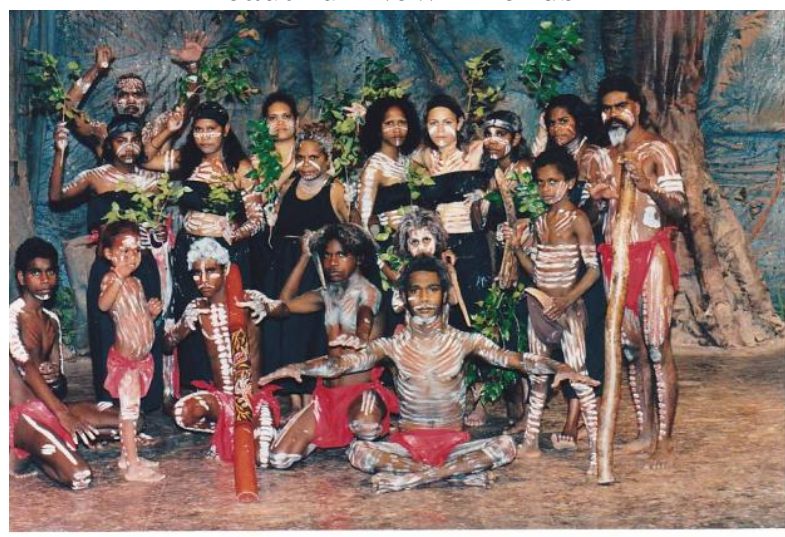

Performance

Writers write and that is what I do. This Hunting Grounds story was written soon after my memorable link with Mayi-Wunba dancers. Extracts may appear fictional but how the story was gifted to me, the spiritual impact of it and why it is written in the first person is true. It is the elder's personal account of one part of his ritual passage into manhood.

\section{Hunting Grounds.}

I sit in a tribal circle listening to the elder. He directs his bony finger at the young men.

"You go to the pub, get drunk, beat each other up and you think that makes you a man? Wrong!"

No one speaks, either in English, or Djabugay.

I am captivated by this deep soft voice, mesmerized by his appearance. The moon grey hair and matted beard, round eyes amber-brightened by firelight, hold us in awe. His lean body sings rhythmically demanding our attention.

White totem marks glint on the brown bodies surrounding me. I have watched them become the totems they bear. Their agile warrior limbs become those of crocodile, kangaroo, snake or cassowary with movements mimed to perfection. Innate rhythms that resemble creatures of the rainforest come naturally to these tribal dancers. In performance they become the animals that have moved in their bloodstream since they were conceived. Their totems are their soul's lifeblood. 
Now they are still, listening to an elder's wisdom. His voice is back-grounded by plaintive sounds of didgeridoo and night rainforest calls. The sudden flight flurries of fruit bats and the swirling cascades of the Bulurru sacred waters are peripheral sounds that honour his storytelling.

The present moves away from me. Time glides sideways, then backwards, with his words. Gradually my consciousness dissolves.

I slip into the long-legged body of a young boy living in a tribal village bayu, home, where lawyer-cane huts skirt the church mission reserve. My Gurra gurra ancestors, built mia mias there.

I tag along behind my mother and grandmother searching for roots and berries, nuts and grains. For me this is the work of women, and my heart longs to join the hunters. I am told that day will come, as I gather shellfish from the glistening beach or catch large nyinggarra, the shining eels from the running storywaters.

I grow stronger and taller. Patient and stealthy, I follow the feather on the thread of hair, my brother ties to the plump native bee. When it flies back to its nest in the treetops, I am close behind. I climb with ease. Before long I have brought the golden food of the honey hive to earth. The tribe will be sweet tonight. This mayi-wunba brings us both food and medicine. I am praised for my honey gathering, but my heart still pounds to be a warrior.

My longing is intense to join the hunters. Soon, I am told, as I fish in the surf with my brothers, or trap small goanna and lizards for grandmother to roast. Soon? When is soon? When will I have the chance to prove my strength and courage?

Finally it is decided. Tomorrow I join the hunters. My brothers are disturbed and cross because I cannot sleep. I toss and turn watching the moon creep over the dark rainforest hills. At dawn I stretch my limbs in the bronze light of day. Then directed by the elders I commune with Gudju-Gudju the Rainbow Serpent.

It is right to do so because today I join the hunters to bring back kangaroo meat for the tribe. Not only does the dulbil give us fine meat it provides us with blankets and waterbags.

Today I take a large step in my life. Today I hunt to be recognised as a man. Then I will be fully prepared for other initiation rituals. My older brothers do not speak of their own rituals, but I know that just as the sacred story time is inscribed on the land, so it is upon their bodies. I have seen the signs on their shoulders, chests and stomachs. Maybe today I will kill dulbil for bones, teeth, nails and claws to make decorations for the corroboree. Yes, I will hunt the kangaroo and make my tribe proud of me. This is my dreaming. This is what I was born for.

We are away in the cool morning sunshine. There are only a few horses, so I ride behind my father. We go with wagays wooden swords, spears and clubs. The men rely on instinctive tracking skills for our direction.

I try to be included in snatches of Djabugay. I want to be the hunter today. Sometimes my father indicates that silence is necessary. 
The sun's intensity increases. Patches of rainforest provide welcome shade. The hours pass as we concentrate on the calls of birds and the sounds of small creatures scattering as we pass. We move gently through ferns, then scrub land on little known tracks, until we come across a large clearing. As we leave the shadows of dappled light below the trees and edge into the brighter sunlight we note the large buck dilbul grazing in the open scrub.

I wait for one of the adults to give us commands. Surely, soon a spear will be aimed. We are so very close now. He has not noticed us. Dismounted, we creep ahead slowly and stealthily. Soon we are even closer to him and he is not moving. My club is tight in one hand, a spear in the other. I know how fierce a dilbul can be. His legs are bullock strong and he is fast with kicks and severe body blows. This one is almost twice my height.

Still no spear whistles out. I look around to discover I am alone. I am alone facing this large buck.

The adults have disappeared. In a flash I understand.This is my hunt. It is mine alone, and I have nothing but a spear and a club in my sweaty hand. He knows I face him. Time stands still. Our eyes meet. They record instant decisions for fight or flight.

He makes a swift sure movement to run .As he does I take direct aim and thrust my spear toward his body. I miss. He was too quick for me this dulbil. In the space between us I run, retrieve my spear to see he has stopped in his tracks. He is prepared for battle. I aim again and pierce his side. His cry rents the stillness. I rush forward ready to club him down. I aim toward his head and see the anger in his eyes. He doubles up but is still boxing out with massive fore legs. Again and again we meet, blow for blow. His attacks are as deadly as those I land on his head and forequarters.

The blows take their toll. His life blood oozes from the spear wound. My head reels from the blows which he has planted with deadly accuracy.

We are both weakening. Now he is down and I muster all my energy to straddle him. I pin his legs beneath my own. Then my hands close around his neck to take his breath away. Now it is surrender, not anger in his eyes. It is over.

We lie together warm and still, beneath the fading sunlight. My breath slows down. The dulbil's has stopped. My heart still pounds .It is an eternity before I move away from the soft warm skin.

Now, another challenge. I must drag, lift, or somehow carry my kill, my dulbil back to the tribe. My triumph is overshadowed by the weakness in my legs. The toll of the battle had been greater than I realised. I know instinctively what I must do to regain energy and direction. I take time to commune with Gudju-Gudju the Rainbow Serpent to honour my dulbil and praise his courage.

Later I drag my beautiful animal out of the clearing. It takes time and strength. There at the edge of the shadowed forest stands my father's horse. I smile to myself. He has shown trust in me to return to the village. I finally manage to load my dulbil and mount myself, to take the long track homeward. 
Though my head still throbs I am proud to bring home meat for the tribe. My grandmother will begin the skinning and before long the smell of roast meat will be welcomed by all. I will enjoy that meal.

\section{But it wasn't like that. My greatest lesson was yet to come.}

Grandmother welcomes the dulbil and starts to prepare and cook the fine meat. I am directed to a bayu where I must remain for many hours. Alone, hungry I can smell that meat. My anger wells up inside. I am the hunter! I deserve praise and honour! I used all my energy and here I am, hungry and unloved. Surely I, the hunter deserve the best of the meat? Finally I sleep, aching and empty.

The next day I stand in the tribal circle, still hungry and sore from the battle. Resentful, I do not wish to hear the words directed to me.

Gradually, very gradually I understand the valuable wisdom of this way. I learn that the hunter hunts not for himself but for the tribe. This is the law of the tribe. This is how it will survive. The tribe must always come first, in everything. No matter what the sacrifice of the hunter. I fought and hunted well but my rite of passage only began with that hunt. My lesson was the night of hunger, hurt pride, and the painful wounds which made me simmer with anger, the night when the women, children and my hunting brothers ate to fill their hungry bellies.

That is how it should be. Honour for the meat and honour for the hunter, but only after the tribe is full. It is the understanding of this that is the rite of passage of the true warrior.

Slowly my own body comes back to me as the young hunter I had become, moves out of the time and space of my mind into the astral realms from whence he had materialized. I am me, an elderly Kiwi teacher sitting in the tribal circle.

As the moonlit elder closes his personal story the young men around me are silent. They have heard more than a hunting tale. They were given the essence of their tribal law. I had been given a gift that defies explanation.

When the time came for farewells to my new rainforest family I left with the taonga of my totem. My name is Gaway. In Djabugay it means "Guiding Star".

I am indebted to the rainforest family for the spiritual experience and totem given me. That experience in the rainforest of Queensland changed my life. As a teacher and educator from another land, I returned home wondering who was guiding whom in this my own dreaming.

\section{Authors Note}

Nothing as Posh as a Memoir by Hazel Menehira FTCL ISBN 978-0- 98739864-2

Copies available from Collins Bookshop, Smithfield, Cairns Queensland Aus. 
Paiges Bookshop, Guyton St, in Wanganui N.I. N.Z.

It is also now available to download as an Amazon ebook to any pc or reader on this link Nothing as Posh as a Memoir - Amazon eBook - Hazel Menehira

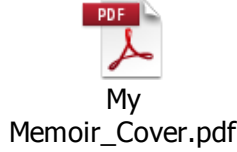

